\title{
A educação no campo na perspectiva dos alunos que buscam superar os limites educacionais do contexto rural
}

\author{
Education in rural areas from the perspective of students seeking to overcome \\ the educational limits of the rural context
}

\author{
Aziel Alves de Arruda ${ }^{1}$ \\ Noelia Mesquita Conceição ${ }^{2}$ \\ Ricarte Tavares ${ }^{3}$
}

\begin{abstract}
RESUMO
O presente trabalho discute a respeito da historização da educação para o contexto rural, fazendo uma ressalva acerca da marginalização que a população rural sofre no âmbito das políticas educacionais. Nesse contexto, é pontuado a importância dos movimentos sociais do campo na conquista de alguns avanços. Partindo desse pressuposto, busca-se, a partir desse trabalho, analisar a realidade educacional a partir das leis e abordagens teóricas; investigar o que as leis asseguram em relação à educação para o contexto rural, para que seja possível refletir sobre por que há tantos jovens excluídos da escola por falta de oportunidade; compreender quais são os principais bloqueios que comprometem o avanço da educação para a população rural. Entretanto, no que cerne a metodologia, utilizamos como instrumento de investigação, a pesquisa bibliográfica com intuito de elencar a historização da educação rural e as políticas públicas que asseguram essa perspectiva educacional.
\end{abstract}

Palavras-chave: Educação rural; Políticas públicas; Movimentos sociais.

\section{ABSTRACT}

This paper discusses the historicization of the rural context education, making a remark about the marginalization that the rural population suffers in the scope of educational policies. In this context, the importance of rural social movements in achieving some advances is highlighted. Based on this assumption, it is sought through this work, to analyze the educational reality from the laws and theoretical approaches; investigating what the laws ensure in relation to the rural context education, so that it is possible to reflect on why so many young people are excluded from school due to the lack of opportunity; understand what are the main obstacles that hinder the advancement of education for the rural population. However, as far as the methodology is concerned, we use bibliographic research as a research tool in order to list the historicization of rural education and the public policies that uphold this educational perspective.

Keywords: Rural education; Public policy; Social movements.

\footnotetext{
${ }^{1}$ Doutor em Educação, Professor da Universidade Federal do Maranhão (UFMA) - Campus Codó, email: azielalves@gmail.com

${ }^{2}$ Graduanda do curso de Licenciatura em Pedagogia, Universidade Federal do Maranhão (UFMA) Campus Codó, e-mail: danielapess4@gmail.com

${ }^{3}$ Mestre em Ciências, Universidade Federal de Alagoas (UFAL), e-mail: ricarttavares@ hotmail.com
} 


\section{Introdução}

Para compreender a dicotomia entre a educação rural e a educação do campo, torna-se indispensável pontuar as principais distinções entre essas duas perspectivas. Educação rural é uma perspectiva educacional que visa atender aos interesses capitalistas no que cerne ao desenvolvimento econômico do país e que carrega para o ensino os anseios da elite agrária: os empresários e latifundiários do agronegócio.

É uma educação tida como assistencialista para aquela população considerada desprovida de direitos e cidadania, desse modo, o controle político é algo marcante, objetivando fixar o camponês no campo para que sua força de trabalho barata e desqualificada some no crescimento econômico. Nesse sentido, trata-se de uma educação que tem como referência a pedagogia tradicional que acaba reforçando o discurso da incapacidade intelectual do homem do campo, fazendo com que se acomode com a situação de oprimido, e, assim, o medo e a falta de discurso se solidifiquem.

Ressalta-se que a educação do campo teve início com a luta dos movimentos que atuam no campo, que, em cenário de muita luta e resistência, despertaram o seu olhar para a reivindicação da garantia de políticas públicas educacionais que viessem a atender os seus interesses, ou seja, uma perspectiva educacional capaz de suprir as necessidades do camponês e dos movimentos sociais do campo, tendo como referência a pedagogia libertadora/oprimido e histórico, em que o homem do campo é o centro do processo educacional, com práticas educacionais transdisciplinares que atendem à formação cidadã desses indivíduos, com também visa atender os seus interesses econômicos. Dessa forma, a educação do campo é adequada ao modo de vida no campo, pois seu currículo, calendários escolares são adequados às peculiaridades do local, como também busca inserir professores conterrâneos.

A educação rural deve estar sempre em pauta nos debates em prol da melhoria da educação de modo geral, por ser uma pauta que por vezes é esquecida pelo governo, com falta de investimento. $\mathrm{Na}$ trajetória da educação rural, os indivíduos pertencentes a esse meio sempre foram concebidos como exemplo de atraso, e as políticas educacionais se organizavam em conformidade com os interesses capitalistas predominantes em cada conjuntura. Embora se tenha conquistado muitos avanços em prol da educação rural devido aos movimentos sociais que discutem e reivindicam por políticas educacionais que venham a sanar os caos da educação rural, esses avanços ainda não atingiram o público rural como um todo, pois muitos municípios continuam estagnados em relação a esse tipo de educação que compromete a emancipação do homem do campo.

$\mathrm{Na}$ Lei 9.394/96 (LDB), as mudanças vão aparecer no artigo 28, quando estabelece as normas para a educação do campo:

Art. 28 - Na oferta da educação básica para a população rural, os sis- 
temas de ensino proverão as adaptações necessárias à sua adequação, às peculiaridades da vida rural e de cada região, especialmente:

I- Conteúdos curriculares e metodologias apropriadas às reais necessidades e interesses dos alunos da zona rural;

II- Organização escolar própria, incluindo à adequação do calendário escolar às fases do ciclo agrícola e às condições climáticas;

III- Adequação à natureza do trabalho na zona rural. (BRASIL, 1996, $\mathrm{s} / \mathrm{p})$.

De acordo com a história da educação, a educação rural foi uma educação tecnicista voltada para o campo sem considerar suas particularidades. A educação para os trabalhadores rurais teve sua origem quando o Brasil se tornou república em 1889, tida como assistencialista objetivando apenas atender os interesses do sistema capitalista com práticas transferidas da cidade que necessariamente vinha a valorizar a vida na cidade em rejeição ao modo como as pessoas do campo vivem. Conforme as diretrizes curriculares da educação no campo, as ações governamentais eram influenciadas pela política norte americana.

Entretanto, a partir de estereótipos atribuídos ao campesino como instrumento para o trabalho agrícola, tratado com ofensa, menosprezo e incapacidade, a população inserida em regiões rurais era apontada como intelectualmente inferior na visão das elites agrárias servindo apenas como trabalhadores desprovidos de direitos e de cidadania.

Vale ressaltar que essa visão distorcida ainda perpetua nos dias atu- ais, até mesmo nos bancos escolares em que o campo é visto com um olhar equivocado. Para Molina e Fernandes (2004), a perspectiva de educação rural estava relacionada a uma ideia de educação defasada, desatualizada, sem o mínimo de qualidade ou recursos para o desenvolvimento dos alunos. Tais expressões depreciativas reforçam o descaso e falta de políticas públicas para o universo campesino, fazendo com que a emancipação do homem rural se torne cada vez mais distante, o que acaba comprometendo muitas vidas.

\footnotetext{
Implantar projetos educacionais na zona rural e o desenvolvimento das comunidades campestres, mediante a criação de Centros de treinamento (para professores especializados que repassariam as informações técnicas aos rurícolas), a realização de Semanas Ruralistas (debates, seminários, encontros, dia de campo, etc.) e também a criação e implantação dos chamados Clubes Agrícolas e dos Conselhos Comunitários Rurais. (LEITE, 2002, p.32)
}

Nos dias atuais, a concepção de educação rural não mudou muito, embora tenha havido alguns avanços para o meio rural, com a aprovação das diretrizes para a educação básica em escolas do Campo; a educação continuada, alfabetização e diversidade (SECAD), criada pelo ministério da educação (MEC), em 2003; grupo permanente de trabalho de educação do campo, através da portaria $n^{\circ} 137 /$ 2003 que visa desenvolver o universo campesino, mas sempre com o intuito de preparar o homem rural para permanecer no seu universo, ou seja, a 
educação para os camponeses ainda não atente totalmente os interesses dos indivíduos, pois nem todos almejam seguir a vida de agricultor. Enquanto alguns visam crescer sem sair do seu lugar, outros sonham em ultrapassar as barreiras e alcançar novos objetivos que são tidos como extremamente distante de sua realidade.

Nesse sentido, a história da classe trabalhadora rural que, desde o final da década de 1980 e início da década de 1990, vem ganhando visibilidade através de mobilizações e atos de resistência aos interesses capitalista. Nessa perspectiva, Gonh (2008, p.159) destaca que "só os movimentos sociais têm a capacidade de reinventar e reorientar o estado e suas políticas e exigir a superação da submissão do estado às políticas socioeconômicas contrárias aos interesses de uma sociedade e de um povo".

Nessa perspectiva, o que nos trouxe a pesquisa foram nossos estudos a respeito desse tema, pois sabemos das inúmeras dificuldades que a escola rural enfrenta, como a falta de uma infraestrutura adequada, falta de recursos, merenda escolar, investimento na formação de professores. Embora haja avanços no sentido de melhorar a educação para o contexto campesino de forma a contemplar as peculiaridades do campo e atender aos interesses desses indivíduos, muitos municípios continuam estagnados na educação rural, além do mais é ofertado somente até o ensino fundamental completo.

Com isso, neste trabalho, procurou-se analisar a realidade educacional a partir das leis e abordagens teóricas; investigar o que as leis assegu- ram em relação à educação rural para que seja possível refletir sobre o porquê de tantos jovens serem excluídos da escola por falta de oportunidades e compreender quais são os principais bloqueios que comprometem o avanço da educação para a população rural. Para tanto, foi realizada uma revisão da literatura a partir de pesquisa bibliográfica. A presente pesquisa abordará a seguir os seguintes tópicos: "Contextualização histórica da educação para o meio rural no Brasil" e "A dicotomia entre educação no campo e educação do campo".

\section{Contextualização histórica da educação para o meio rural no Brasil}

De acordo com a contextualização histórica da educação no campo no Brasil, a educação rural foi o único projeto educacional, com a lógica da educação urbana, que, ao ser comprado com o contexto do campo, necessariamente desvaloriza os saberes, práticas e culturas desses indivíduos, de modo que sutilmente reforça as desigualdades e exclusão. Trata-se de uma educação ligada ao desenvolvimento econômico do país. Em razão disso, o campo sempre foi marginalizado no âmbito das políticas públicas.

Portanto, no contexto na intensificação da industrialização brasileira, os indivíduos do campo passaram a migrar para a cidade em busca de melhores condições de vida, o que é considerado negativo para a elite agrária, pois eles precisam desses trabalhadores. A educação rural começou a ser pensada como estratégia de barrar esse 
fluxo migratório e, assim, fixar aqueles indivíduos ao campo para atender às expectativas da elite por meio de sua mão de obra barata.

As primeiras escolas em meio à zona rural que foram construídas não funcionavam, sobretudo as escolas agrícolas, pois não possuíam o material necessário. A lógica da construção dessas escolas eram as mesmas das escolas urbanas (MARINHO, 2008).

Nessa perspectiva, no contexto meramente tecnicista, o contexto campesino só foi "contemplado" em aspectos educacionais por quatro razões: a instituição da diferença entre as ideias de cidade e de campo; a crise de 1929; a ascensão de Getúlio Vargas ao poder; e a início da alfabetização de jovens e adultos no campo.

Entretanto, somente na constituição de 1934, aparece indicativo da relevância da educação para o cenário rural, sendo citada em nível nacional. Afinal, a educação para os trabalhadores rurais passou a ser repensada no sentido de ultrapassar os interesses capitalistas e tecnicistas. Nesse viés, em 1930, recebeu a nomenclatura de política, mas foi legitimada do ponto de vista legal somente em 1934.

Ao se analisar a contextualização histórica da educação no Brasil, é perceptível que o modelo educacional sempre foi excludente. A escola brasileira de 1500 até o início do século $\mathrm{XX}$ foi tida como privilégio para a elite, sendo inacessível para grande parcela da população, como os negros, trabalhadores rurais, mulheres e indígenas, pois, na visão da classe dominante, esses sujeitos naturalmente não precisam ler e escrever, porque, para desenvolver o trabalho agrícola e os serviços tidos como submissos, o letramento era desnecessário. Portanto, quando se trata da educação para os trabalhadores rurais, fica explícito o descaso do estado nas perspectivas das políticas pública educacionais.

De acordo com Caldart:

Defendemos com tanta insistência a necessidade de política e projetos de formação das educadoras e dos educadores do campo. Também porque sabemos que boa parte deste ideário que estamos construindo é algo novo em nossa própria cultura. E que há uma nova identidade de educador que pode ser cultivada desde este movimento por uma educação do campo. (CALDART, 2002, p. 36)

Historicamente vem se estabilizando o campo apenas para atender aos interesses capitalistas. A partir desse ideário, é possível elucidar que o conhecimento intelectual seria desnecessário para os trabalhadores rurais, tratando-os apenas como instrumento para o trabalho. Os indivíduos que vivem no campo são tidos como desprovidos intelectualmente, culturalmente atrasados e inferiores em todos os aspectos. Esses resquícios ainda perpetuam na atualidade. Até mesmo nos bancos escolares, de modo que os estereótipos atribuídos ao sujeito são menosprezam seu modo de vida, seus saberes, enfim, sua cultura.

Ressalta-se que a educação no/do campo é indissociável da reforma agrária brasileira. Tal afirmação fica explícita na contextualização histórica, quando nos referimos a concentração fundiária no Brasil no final do século XVIII, quando os trabalhadores 
passaram a não ter total liberdade para permanecer nas terras. $\mathrm{O}$ controle dessas terras ficaria sob o controle da elite. Nesse cenário, o império decreta a lei de terras de 1950. A partir dessa lei, o acesso às terras se tornou privado, assim só se teria posse de terra por meio do capital. Tal processo foi marcado pela desigualdade social e exclusão de grande parte da população, inclusive a população rural.

A população rural, como os lavradores, escravos "recém-libertos" entre outros, era desprovida economicamente. Para manter sua sobrevivência, ficou submissa a força de trabalho de subemprego dos fazendeiros. Porém, perante essa situação, houve uma intensificação da população rural. No segundo império, surgiu a necessidade da escolarização no campo, que necessariamente era controlada pela elite, como forma de manipulação dos sujeitos, pois, além da alfabetização ser considerada desnecessária para os trabalhos braçais, também, quando menos conhecimentos esses indivíduos possuísse, menor as chances de ser controlados.

Portanto, quando se trata de os sujeitos terem reconhecidos seus direitos, torna-se indispensável a contribuição do escritor Paulo Freire, o qual, por meio do seu método de alfabetização, buscou, além de ensinar a leitura, também despertar o senso crítico dos indivíduos. Freire preconizava que não basta apenas ensinar o instrumento da escrita, mas também criar ferramentas para interpretar o mundo. Quando se trata de escolarizar o homem do campo, não basta apenas alfabetizar, mas também despertar o seu olhar acerca do mundo para torná-lo conhecedor de seus direitos como cidadãos.

Afinal, para abordar a historização da educação rural, como também suas conquistas, é indispensável descrever a importância dos movimentos sociais da população campesina, que, embora gradativas, trazem melhorias para esses indivíduos. Nesse sentido, há os movimentos sociais que deram voz ao homem do campo ao conseguir reivindicar seus direitos.

\section{A dicotomia entre educação no campo e educação do campo}

Historicamente a educação rural foi o único projeto voltado para o contexto rural, sendo uma perspectiva educacional que tem como referência a cidade, que, ao comparada com a vida no campo, necessariamente desvaloriza os saberes, as práticas e culturas dos indivíduos do meio rural. Partindo do pressuposto da pedagogia tradicional e do "improviso" com currículos, calendários escolares e professores oriundos da cidade, parte de um ensino fragmentado não considera as peculiaridades do universo campesino.

Entretanto, a educação para os camponeses é construída a partir de valores externos, com uma transposição didática do meio urbano para o meio rural, que necessariamente reforçam as desigualdades sociais e desvalorizam o modo de vida desses indivíduos, levando-os a considerar suas culturas inferiores. Trata-se de uma educação que sutilmente torna os sujeitos do meio rural cada vez mais passivo, de modo que o comodismo se 
intensifique com a situação de oprimido, em que o medo da liberdade se solidifica no medo e na impropriedade do discurso.

Afinal, é uma educação desconexa de sua função social, que é formar cidadãos, pessoas que sejam conscientes de direitos e deveres, e que saiba fazer a leitura do mundo, pois não basta apenas alfabetizar, mas também orientar o aprendiz a usar seus conhecimentos em suas práticas sociais. Segundo Molina,

Fazer essa redução é extremamente grave porque tira a dimensão do conflito, da luta de classes, reduzindo-a aos processos de ensino aprendizagem que ocorrem no ambiente escolar. Estes processos são importantes e é necessário incidir sobre eles, pois ao fazer isso, também incidimos sobre como vai se constituindo a leitura de mundo dos educandos - apesar de ser muito mais que isso o desafio e a tarefa da Educação do Campo. (MOLINA, 2015, p.382)

Em contrapartida, a educação rural/educação do campo é um projeto que vem sendo construído paulatinamente em um cenário de muitas lutas e resistência dos movimentos da população rural como o movimento dos trabalhadores sem terras (MST), que, a partir da conquista de um lugar para morar, passaria reivindicar por necessidades básicas, entre elas a educação, mas não tratava apenas do acesso à educação, pois o MST almejava uma educação que viesse atender os anseios da população do campo.

Nesse viés, essa nova concepção de educação para o campo tem como referência a pedagogia libertadora/oprimido e histórico crítica, com currículo e calendário escolar voltado para as especificidades dos sujeitos do campo e com professores conterrâneos da própria comunidade. Quanto às práticas educacionais, o ensino é adequado ao modelo sustentável, com base nos interesses dos movimentos sociais do campo.

Afinal, é uma educação construída a partir dos próprios sujeitos do campo; dos valores sociais, econômicos, políticos e culturais. É uma educação ativa porque os alunos são protagonistas da sua própria história, na luta contra os opressores, com base no diálogo e na coletividade.

Nesse sentido, os movimentos sociais da população campesina visam à busca de visibilidade para a população do campo, que historicamente vem sendo marginalizadas no âmbito das políticas públicas, principalmente as políticas educacionais. De acordo com Caldart:

\footnotetext{
Não se trata de 'inventar' um ideário para a Educação do Campo; isso não repercutiria na realidade concreta. O grande desafio é abstrair das experiências e dos debates, um conjunto de ideias que possam orientar o pensar sobre a prática de educação da classe trabalhadora do campo; e, sobretudo, que possam orientar e projetar outras práticas e políticas de educação. (CALDART, 2004, p. 16)
}

Portanto, foi diante da intensificação dos movimentos sociais no Brasil na década de 1990, que conquistou inúmeras contribuições e avanços na luta pela elaboração de um projeto 
educacional que viesse atender aos anseios, respeitando a diversidade. Nesse sentido, a partir do MST, foi possível ter uma nova concepção a respeito da necessidade de uma educação voltada e pensada para o contexto rural, surgindo, assim, a reivindicação por uma educação que viesse a valorizar o modo de vida do homem do campo na escola, com ensinamentos adequados às peculiaridades e necessidades daquela determinada população.

Embora as primeiras discussões sobre a educação do campo tenha se expandido em 1996, ela só foi constituída como política pública em 2008. Considerando essa informação, é possível elucidar que o Brasil ainda tem muito que avançar no sentido de dar visibilidade para efetivar uma verdadeira concepção de educação para o campo, com uma educação que cumpra a sua função social: formar cidadãos críticos e conscientes de seus direitos, capazes de lutar por eles por meio de um discurso bem sólido e coerente.

\section{Considerações Finais}

Nessa perspectiva, a educação idealizada para o meio rural trata de um sistema educacional excludente que de início tinha o intuito de barrar a migração do campo para a cidade devido à intensificação da industrialização, quando o homem do campo estava em busca de melhores condições de vida. Porém, essa educação tinha como estratégia manter a ordem e o controle sobre os trabalhadores rurais com uma educação instrumental voltada para formar apenas trabalhadores para $o$ universo rural. Entendimento do campesino como subnutrido, pobre e ignorante, a educação era vista com o objetivo de proteção e assistência ao camponês, sem considerar os anseios e tampouco as particularidades do universo campesino.

\begin{abstract}
No âmbito da educação do campo, objetiva-se que o estudo tenha a investigação como ponto de partida para a seleção e desenvolvimento dos conteúdos escolares, de forma que valorize singularidades regionais e localize características nacionais, tanto em termos das identidades sociais e políticas dos povos do campo quanto em valorização da cultura de diferentes lugares do país. (PARANÁ, 2010, p.31)
\end{abstract}

Quando se trata de avanços na educação do meio rural, os movimentos sociais têm o seu destaque, pois foram eles, sobretudo o movimento dos povos sem-terra (MST) que, durante uma longa trajetória, alinhou estratégias de luta e resistência por políticas públicas voltadas para o contexto campesino, uma educação capaz de atender as demandas do homem do campo, levando ao desenvolvimento pleno do mesmo.

Com isso, podemos observar as conquistas e avanços da educação do campo, mudanças essas que, ao longo dos anos, vem sendo conquistadas por essas pessoas. Houve várias lutas para que essa comunidade fosse atendida de forma adequada, mas sabemos que ainda precisa de mais políticas públicas que possam englobar esse público, oferecendo mais oportunidades educacionais. 


\section{Referências}

BRASIL, MEC; Programa Nacional de Educação do Campo: Pronacampo. Brasília/ DF: MEC, março de 2012. Disponível em http://www.consed.org.br/images/phocadownload/ pronacampo.pdf. Acesso em 20 de novembro de 2019.

Lei de Diretrizes e Bases da Educação Nacional 9394/96. Disponível em: <http://www.planalto.gov.br/ccivil_03/leis/19394.htm>. Acesso em: 20 de novembro 2019.

CALDART, Roseli Salete; ARROYO, Miguel Gonzáles; MOLINA, Mônica Castagna. (Orgs.). Por uma Educação do Campo. Petrópolis, RJ: Vozes, 2004.

Roseli Salete (orgs.). Educação do Campo: Identidade e Políticas Públicas. - Brasília, DF: Articulação Nacional por uma Educação do Campo, 2002. Coleção Por uma Educação do Campo, nº 4.

FERNANDES, Bernardo Mançano; MOLINA, Mônica Castagna. O campo da educação do campo. Por uma educação do campo: contribuições para a construção de um projeto de educação do campo. Brasília: Articulação Nacional "Por Uma Educação do Campo, 2004, 53-91.

GONH, Maria da Glória. Conselhos municipais de acompanhamento e controle social em Educação: participação, cidadania e descentralização. In. SOUZA, Donaldo Bello de (org.). Conselhos municipais e controle social da educação: descentralização, participação e cidadania. São Paulo: Xamã, 2008.

LEITE, Sergio Celani. Escola Rural: urbanização e políticas educacionais. São Paulo: Cortez, 1999.

MARINHO, R. E. Um olhar sobre a educação rural brasileira. Brasília: Universia, 2008.

MOLINA, M. C. Educação do campo e o enfrentamento das tendências das atuais políticas públicas. Viçosa: Educação e perspectiva, v.6, n.2, p. 378-400, jul/dez, 2015.

PARANÁ. Diretrizes Curriculares da Rede Pública de Educação Básica do Estado do Paraná - Educação do Campo. Curitiba/PR, 2006. 
SANTOS, Ramofly Bicalho. História da educação do campo no Brasil: o protagonismo dos movimentos sociais. Revista Teias, 2017, 18.51: 210-224.

SILVA, Iara Souza. Ensino de história na educação do campo: novos olhares e outras propostas pedagógicas. 2018. 118 F. Dissertação (mestrado) - História, ensino e narrativas, Universidade estadual do Maranhão, São Luís, 2018.

$O(s)$ autor(es) se responsabiliza $(m)$ pelo conteúdo e opiniões expressos no presente artigo, além disso declara(m) que a pesquisa é original.

Recebido em 13/03/2020

Aprovado em 19/06/2020 